\section{Differential Response of Barley Varieties to Manuring.}

IT is a well-known fact that, by selection or hybridisation, varieties of any one plant can be produced which differ markedly in their yielding capacity. It is generally undecided as to what this difference of yielding capacity is due, and although yielding capacity of plants is controllable by manuring, it is not known whether the increase in yield gained in this way is a function only of the manure added, or whether different varieties respond to varying extents to the manurial combinations given. Interesting results were obtained in an investigation which has been carried out to test the efficiency in the use of

TABLE I.

scale of manuring Employed (gm. per pot).

\begin{tabular}{|c|c|c|c|c|c|c|c|c|c|c|c|}
\hline & \multicolumn{3}{|c|}{$\begin{array}{l}\text { Phosphate-deficient } \\
\text { Manuring. }\end{array}$} & \multirow{2}{*}{$\begin{array}{c}\text { Complete } \\
\text { Manuring. } \\
\text { D. }\end{array}$} & \multicolumn{3}{|c|}{$\begin{array}{l}\text { Nitrogen-deficient } \\
\text { Manuring. }\end{array}$} & \multirow{2}{*}{$\begin{array}{c}\text { Complete } \\
\text { Manuring. } \\
\text { H. }\end{array}$} & \multicolumn{3}{|c|}{$\begin{array}{l}\text { Potash-deffcient } \\
\text { Manuring. }\end{array}$} \\
\hline & A. & B. & c. & & E. & F. & $\vec{G}$. & & I. & J. & $\overline{\mathbf{K}}$. \\
\hline $\mathrm{P}_{2} \mathrm{O}_{5}$ & 0 & 0.02 & $0 \cdot 10$ & $0 \cdot 50$ & 0.50 & 0.50 & 0.50 & $0 \cdot 50$ & 0.50 & 0.50 & 0.50 \\
\hline & 1.50 & 1.50 & $1 \cdot 50$ & 1.50 & 0 & 0.06 & $0 \cdot 30$ & 1.50 & 1.50 & 1.50 & $1 \cdot 50$ \\
\hline $\mathbf{K}_{2} \mathrm{O}$. & 1.00 & 1.00 & 1.00 & 1.00 & $1 \cdot 00$ & 1.00 & 1.00 & 1.00 & 0 & 0.04 & $0 \cdot 20$ \\
\hline
\end{tabular}

A yield significantly greater in favour of the first variety is shown by $a_{+}+$, while a - indicates that the second variety has produced a significantly greater yield; zero indicates no significant difference in yield. It will be seen that for any one pair of varieties the relative magnitude of yield differs in an orderly way with the manuring; thus where a significant increase of the first variety over the second was obtained in the phosphate-deficient combinations, the order is reversed in the potash-deficient sets, and so on. Furthermore, even where no significant differences are found with complete manures, such differences show themselves in the partially deficient sets.

The facts presented in Table II. establish a difference in efficiency in the use of manures by these varieties, and further show that for different varieties tested over the same range of manurial combinations, it is not always the same manurial constituent which in minimum has the most marked effect on relative yield.

The agricultural bearings of the results obtained are twofold: (1) Varietal trials must be combined with manurial trials to be com-

manures by five well-known varieties of barley. Eleven manurial combinations consisting of different amounts of phosphate, nitrogen, and potash were used. The experiments were done in pot culture, using pure sand and solutions of pure chemicals. Each manurial combination was replicated seven times, giving in all 385 pots. The manurial scheme is tabulated below. The varieties used were Goldthorpe, Plumage, English Archer, Plumage Archer, and Spratt Archer.

Varietal differences in response were apparent in all the types of manuring. The difficulty of separating variations in yield due to experimental error from differences in yield due to manurial treatment, varietal differences in general, and differential varietal response to the various manures, was met by application of R. A. Fisher's 'Analysis of Variance.' By this means it has been possible to separate out the various effects, and to estimate their significance.

The effect of immediate interest here is the differential varietal response with the different manures. This is shown in the table below where the varieties are compared in pairs.

TABLE II.

Total Dry Weight of Tops. Significance of Varietal DIFFERENCES.

\begin{tabular}{|c|c|c|c|c|c|c|c|c|c|c|}
\hline \multirow[t]{2}{*}{ Comparison. } & \multicolumn{3}{|c|}{$\begin{array}{c}\mathrm{P}_{2} \mathrm{O}_{5} \\
\text { Starved. }\end{array}$} & \multicolumn{3}{|c|}{$\underset{\text { Starved. }}{\mathrm{N}}$} & \multicolumn{3}{|c|}{$\begin{array}{c}\mathbf{K}_{2} \mathrm{O} \\
\text { Starved. }\end{array}$} & \multirow[t]{2}{*}{ Complete. } \\
\hline & & B. & & & & G. & I. J & . & K. & \\
\hline P. with G. & 0 & & & 0 & 0 & & & & & + \\
\hline E. A. with G. . & & + & & & + & & & 0 & - & + \\
\hline $\begin{array}{lll}\bar{P} . \text { A. } & \text { G. } \\
\text { S. A. } & \text { G. : }\end{array}$ & & $\begin{array}{l}0 \\
0\end{array}$ & $\begin{array}{l}0 \\
0\end{array}$ & + & + & + & & $\begin{array}{l}0 \\
0 \\
0\end{array}$ & - & + \\
\hline E. A. , P. . & 0 & 0 & + & + & t & 0 & & 0 & 0 & 0 \\
\hline $\begin{array}{lll}\text { P.A. } & \text { P. } & \text { P. }\end{array}$ & $\underline{0}$ & $\overline{-}$ & $\stackrel{0}{0}$ & $\begin{array}{l}0 \\
+\end{array}$ & 0 & 0 & 0 & 0 & $\begin{array}{l}0 \\
0\end{array}$ & $\begin{array}{l}0 \\
0\end{array}$ \\
\hline & & & & & & & & & & \\
\hline S. A. " E. A. & - & - & & + & & - & 0 & 0 & 0 & 0 \\
\hline S. A. , P. A. & 0 & 0 & 0 & + & - & - & 0 & 0 & - & 0 \\
\hline
\end{tabular}

+ indicates a significant positive difference.

- indicates a significant negative difference.

0 indicates no significant difference.

The absence of significant differences in Series $\mathbf{I}$ and $\mathbf{J}$ is almost certainly due to the great variability in these two sets. plete, and (2) the lines along which to develop selection and breeding of varieties to meet the requirements of different soil types are indicated.

F. G. GREGory.

F. Crowther.

Imperial College of Science and Technology, London, Dec. 3, 1927.

\section{The Nebulium Spectrum in New Stars.}

IN a recent communication (NATURE, Jan. 7, p. 12) C. T. Elvey has applied the 'expanding shell' theory of novæ to calculate the maximum density at which oxygen can be made to give the nebulium spectrum. In Nova Aquilæ, No. 3 (discovered June 8, 1918), the line $\lambda 5007$ was first seen on June 27 , when its breadth was $55 \mathrm{~A}$. ; and the gases are therefore assumed to have been travelling outwards for 19 days with a velocity of $1700 \mathrm{~km}$./sec. before reaching a low enough density to emit this line. If, then, the phenomena are due to the reversing layer of the star being blown off bodily as a shell of gas, we can find the density in the shell at any moment after the outburst, given the initial density and radius. Elvey finds in this way that at the first appearance of the nebulium lines the gas must have a density of the order $10^{-17} \mathrm{gm}$. $/$ c.c.

There is a serious objection to the foregoing reasoning, however, which becomes apparent if we consider the state of ionisation of the gases concerned. The lines $\lambda \lambda 5007,4958$, and 4363 are due, according to Bowen, to the $\mathrm{O}^{++}$atom, which has an ionisation potential of about 35 volts. We can, therefore, find at once from the Russell-Saha formula the various pressures and temperatures at which $\mathrm{O}^{++}$atoms will just begin to appear (say 0.1 per cent.); and it follows that at the density given, the lowest admissible temperature is $\quad T=13,000^{\circ}$ Abs.,

corresponding to a partial electron pressure $p_{e}=2 \times 10^{-13} \mathrm{~atm}$. (This is about half the total pressure.) Now if we apply Elvey's method to hydrogen, which on June 27 showed bright bands of identical width with that of the nebular ones, it is evident that the hydrogen too must have had a density of the order of $10^{-17} \mathrm{gm} . / \mathrm{c} . \mathrm{c}$. on that date. The condition that it shall not all be ionised (say

No. 3039 , VoL. 121] 